\title{
OSPM: A Design Methodology for Open Strategic Planning
}

\author{
Full papers \\ Alireza Amrollahi \\ Griffith University \\ alireza.amrollahi@griffithuni.edu.au \\ Bruce Rowlands \\ Griffith University \\ b.rowlands@griffith.edu.au
}

\begin{abstract}
Although numerous case studies and a body of theoretical work have addressed the open strategy topic (opening the strategy process to wider stakeholders groups) in the literature, approaches to implement open strategic planning has been less studied. In this study, the principles of design science research are employed, and pragmatic presuppositions from Habermas' theory of discourse and the related literature are used to form a design methodology. The open strategic planning methodology contains a three-level architecture for a planning system, and a strategy process. The architecture component identifies three layers of the planning system. The planning process component explains a set of activities required to develop the strategic plan. The methodology is applied in two case studies and implementation challenges are discussed. This study contributes to the literature by introducing a comprehensive methodology of strategic planning and introduces new theoretical aspects to the field of open strategy.
\end{abstract}

\section{Keywords}

Keywords: Strategic Planning, Open Strategy, Design Science Research Method, Discourse Theory.

\section{Introduction}

The concept of strategic planning was coined in the 1950s and evolved to this date in various aspects. Attention to decentralization of strategic planning is one of the evolutionary areas which in recent years has been combined with the notion of open innovation in Information Systems (IS) research and led to a new concept of open strategy. Open strategy is a new paradigm of strategic planning calling for increasing inclusiveness: receiving strategy idea from people outside of the management team; transparency: providing people outside the management team with access to strategy input, process, and outputs (Whittington et al. 2011), and use of Information Technology (IT) tools (Tavakoli et al. 2015a) in one or several of the activities in the strategy formation process".

While open strategy shares many basic concepts with other areas in the IS literature such as crowdsourcing (Amrollahi et al. 2014a), knowledge management (Morton et al. 2015) and group decision support systems (Bjelland and Wood 2008), there are differences on certain aspects such as task type and the process of decision making requires further IS research (Amrollahi 2015; Tavakoli et al. 2015b). Although a number of case studies on open strategy have been conducted since 2012 (Amrollahi and Ghapanchi 2016; Dobusch and Kapeller 2013; Matzler et al. 2014; Stieger et al. 2012), they tend to be primarily descriptive rather than prescriptive and for this reason only few process models have been proposed in the literature. These descriptive approaches are either theoretical or applicable only to a specific context. To address these shortcomings, the current research aims to develop a methodology of open strategic planning using a design science research approach. A Design Science perspective in this study helps the research to achieve its goals through active and theory based development of the research artefact (a methodology).

In order to form a theoretical basis for the methodology of open strategic planning, this study is informed by Habermas theory of discourse (Habermas 2005) and more specifically the four preconditions of an ideal discourse. This theory is based on the assumption that language and communication are mediums for coordinating actions including organizational actions such as strategic planning. Previous research has 
studied the strategy process as a set of iterative and recursive relationship of talk and text based on which a communicative process model has been developed (Spee and Jarzabkowski 2011). This process of text and talk explains the way organizational communication become more valid and depicts the power relationships between organizational actors through time. According to the above mentioned research we infer that a theory of discourse can provide a basis for clarification of the requirements for the proposed strategy planning methodology.

This study contributes to the strategic planning literature by presenting the first prescriptive study in the field of open strategy that can be applied to a variety of contexts. The methodology is called Open Strategic Planning Methodology (OSPM). The paper outlines a new theoretical perspective to the notion of open strategy through considering Habermas' theory of discourse. OSPM consists of two key elements: IT architecture and a strategy process. The paper claims that these two elements will make it easier for practitioners to implement the open strategy concept. In this paper we apply the methodology in two case studies and the findings are reported to benefit both practitioners as well as academia.

\section{Conceptual issues}

\section{Open strategy}

A more inclusive approach for strategic planning was first highlighted in the strategic management literature in the 1990s (Hamel 1996; Mintzberg 1994; Wolf and Floyd 2013) and was further developed to open strategy in the 2000s (Whittington et al. 2011). Among the documented research on open strategy, only a few have proposed a process (or set of steps) for strategy formulation. For example Dobusch and Kapeller (2013), based on the case of Wikimedia strategic plan, proposed a three-step strategy process that commenced with staffing and announcing (performed by the organization), contributing and discussion (performed by community), and task monitoring (performed collaboratively). Based on a synthesis of a proposed method in a number of case studies, Tavakoli et al. (2015a) also proposed a strategy process model covering three phases. This model however lacks detailed specification on the design of the planning system.

While a number of processes have been suggested in the literature as initial steps of an open strategy process, most of the current literature is narrow and is only applicable to a specific context. Moreover, no comprehensive method can be found to go beyond strategy formulation activities that take strategic actors or the planning system into account. To address these shortcomings the current study uses the principles of design science research to develop a methodology of open strategic planning. The benefits of the proposed methodology, it is claimed, can help practitioners to implement the open strategy approach and benefit from its potential to improve the effectiveness and quality of planning.

\section{Habermas' theory of discourse}

The current study is built on a set of assumptions driven from the work of influential German philosopher Jürgen Habermas and his seminal theory of discourse. This theory has its roots in the theory of communicative action (Habermas 1985) which states an action toward a goal takes place based on a (freely) shared understanding among actors about the reasonability of the goal. While this could be applied to any social co-operation, strategic planning in an organization is no exception.

According to Habermas, discourse is "a processes of argumentation and dialogue in which the claims implicit in the speech act are tested for their rational justifiability as true, correct or authentic" and can coordinate human actions (Bohman and Rehg 2007). The current study uses Aier et al. (2011) interpretation of discourse theory using four pragmatic presuppositions of an ideal discourse as a basis for understanding the requirements. These presuppositions have been adopted from Habermas (2005) and specify that during an ideal discourse: a. No-one capable of making a relevant contribution has been excluded; b. Participants have equal voice; c. Participants are internally free to speak their honest opinion without deception or self-deception; $d$. There is no source of coercion built into the process and procedures of discourse.

Throughout the literature, discourse theory is prominent in the IS discipline (Chiasson and Davidson 2012) and similar concepts have been used in the strategic planning area (Spee and Jarzabkowski 2011). Moreover, the aforementioned presuppositions have been found to be similar with the principles of open 
strategy and for this reason have been selected to inform the design process as one source of requirements for the designed methodology. OSPM assumes that open strategic planning is an instantiation of Habermasian discourse during which stakeholders initiate a free discussion on their strategy ideas and after arriving at agreement it can lead future organizational actions.

\section{Research Approach}

As this study aims to find an approach for implementing the open strategy concept, a prescriptive and inventive approach of research is required. For this reason a design perspective is employed and elements of Information System Design Theory (ISDT) are utilized to develop the planning methodology. According to March and Smith (1995), constructs, models, methods, and instantiations are legitimate outcomes of DSR. Walls et al. (1992), however, advanced a fifth output of DSR as theory building that covers the first three outputs (constructs, models, and methods) (Amrollahi et al. 2014b). An iterative multi-phase approach proposed by Peffers et al. (2007) was selected to guide the study (see Figure 1) and the outputs are explained based on the elements of ISDT (Gregor and Jones 2007). The development of OSPM is informed from the concept of open strategy and presuppositions of Habermas discourse (as kernel theory). Figure 1 illustrates the design of the current study.

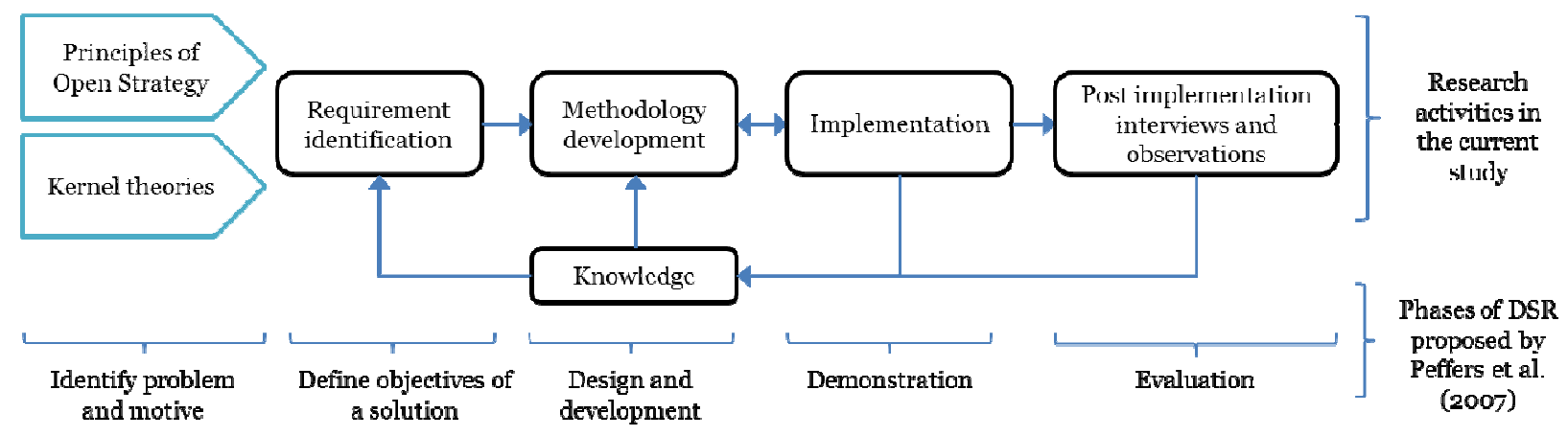

Figure 1. Research design overview

The research design involved two comprehensive case studies. In order to evaluate the suitability of the designed artefact, ex ante (predictive evaluation of the design effort with respect to the future impacts whereas) and ex post evaluations (evaluating both financial and non-financial value) were conducted (Stefanou 2001). In this study ex ante evaluation is performed through primarily discussion with key staff in each case and making sure that the concept of open strategy is suitable for their organisational structure and values, and it is supported by the management team in each case. One source of ex post evaluation reported in this paper were comments and questions by stakeholders during the training workshops, technical challenges of implementation, received comments from users, and stakeholders' dialogue during the planning meetings.

\section{Open Strategic Planning Methodology (OSPM)}

Identification of artefact requirements or purpose have been recognized as the first activity in DSR with various titles such as: meta-requirements (Walls et al. 1992), and purpose and scope (Gregor and Jones 2007). In the current study two sources have been used to identify requirements: (i) related literature (ii) kernel theory. Table 1 illustrates the requirements for design of OSPM and a brief explanation of each requirement.

\begin{tabular}{|lr|l|l|}
\hline Requirements & $\begin{array}{l}\text { Related theoretical } \\
\text { concept }\end{array}$ & Description \\
\hline $\begin{array}{l}\text { Inclusion } \\
\text { exclusion) } \\
\text { stakeholders }\end{array}$ & $\begin{array}{r}\text { (avoid } \\
\text { of }\end{array}$ & $\begin{array}{l}\text { Open } \\
\text { concept / strategy } \\
\text { Presuppositions of a } \\
\text { discourse }\end{array}$ & $\begin{array}{l}\text { Individuals beyond senior managers submit their } \\
\text { strategy ideas: }\end{array}$ \\
\hline
\end{tabular}




\begin{tabular}{|l|l|l|}
\hline Requirements & $\begin{array}{l}\text { Related theoretical } \\
\text { concept }\end{array}$ & Description \\
\hline $\begin{array}{l}\text { Transparency of the } \\
\text { strategic plan and } \\
\text { planning process }\end{array}$ & $\begin{array}{l}\text { Open } \\
\text { concept }\end{array}$ & $\begin{array}{l}\text { "The degree of openness and visibility of the inputs to, } \\
\text { outputs from and the activities of the strategy process } \\
\text { itself." (Tavakoli et al. 2015a) }\end{array}$ \\
\hline $\begin{array}{l}\text { Give equal voice to all } \\
\text { stakeholders }\end{array}$ & $\begin{array}{l}\text { Presuppositions of a } \\
\text { discourse }\end{array}$ & $\begin{array}{l}\text { No advantage will be given to an idea based on the } \\
\text { person who has submitted it. }\end{array}$ \\
\hline $\begin{array}{l}\text { Avoid deception or } \\
\text { self-deception }\end{array}$ & $\begin{array}{l}\text { Presuppositions of a } \\
\text { discourse }\end{array}$ & $\begin{array}{l}\text { Participants are internally free to speak their honest } \\
\text { opinion (Aier et al. 2011; Habermas 2005). }\end{array}$ \\
\hline Avoid coercion & $\begin{array}{l}\text { Presuppositions of a } \\
\text { discourse }\end{array}$ & $\begin{array}{l}\text { There are no sources of coercion built into the process } \\
\text { and procedure of strategic planning (Aier et al. 2011; } \\
\text { Habermas 2005). }\end{array}$ \\
\hline
\end{tabular}

Table 1. The requirements in the current study

After defining the requirements, the next phase in the research process is designing an approach to implement these requirements. Like most of the DSR and ISDT studies, the current study proposes the artefact (methodology) in the form of function and process: the first component of OSPM is the architecture for planning system which describes the structure and function of an information system dedicated to open strategic planning. The second component of OSPM is the strategy process (involving agents and actions) by which the first component will be brought into action. The two components are now described:

\section{Architecture for the planning system}

Following the identification of requirements, a set of principles should be set to describe a class of artefacts designed to meet the requirements (Walls et al. 1992) in form of an abstract blueprint or architecture of an information system (Gregor and Jones 2007). This section of the methodology is introduced below in terms of three components:

Communication: This component of the planning system aims to: a. increase awareness about the project among potential participants and improve the inclusion of selected stakeholders through this, and b. increase awareness about the final developed plan. This is a crucial part of the planning system as it provides a means to fulfil a number of requirements such as: inclusiveness, transparency, and avoiding deception and coercion. It is worth mentioning that some of the features in this component are not fully embedded in the actual planning system, but are performed through other services and offline methods, but they are still meant to form an important part of the artefact and should be dealt with carefully throughout the design activities.

Idea submission: This component creates an informative, transparent, and open mean for participants to enter their strategy ideas for the future of the organization. Idea submission forms guide the participants to align their ideas with the identified high level aims of the organization. As ideas are entered in the planning system anonymously, they give equal opportunity to participants and prevent any pressure or coercion on stakeholders. Moreover, each idea will be also exposed to comments from potential participants and a number of reviewers. These comments will give another opportunity to create a discourse for each specific idea.

Workflow: This component of the planning system manages the flow of ideas. Three groups of stakeholders are involved in the strategy process: (i) research team (people in charge of setting the process, system development, and plan development), (ii) managers (people who make final decisions about the project and strategic plan), and (iii) crowd (all other stakeholders who have been selected as potential participants in the previous phases). The workflow component creates a path for ideas from submission to the final strategic plan and identifies how an idea should go through various stages before being considered in the plan. This flow of ideas will be in accordance with groups of designated stakeholders in the process. Proposed components of the planning system could be considered as layers of architecture for the system. Figure 2 illustrates a multilayer architecture for the planning system. 


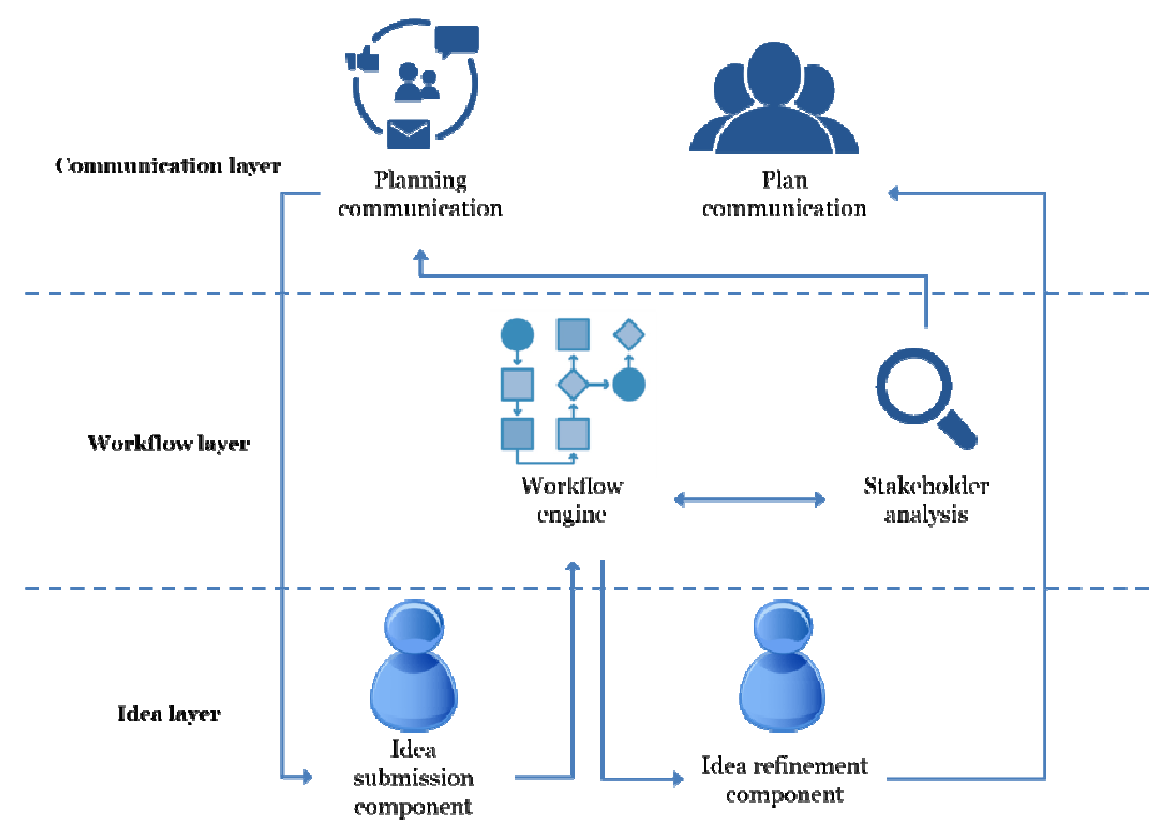

Figure 2. Multi-layer architecture for the system

\section{Planning process}

This study also proposes a process for implementation of the open strategy concept. This part of OSPM can be compared with the design method of Walls et al. (1992) or principles of implementation in the ISDT literature describing how the method or product could be implemented (Gregor and Jones 2007). The three-phase planning process in this study has been proposed based on: previous practices of open strategy and increasing strategy process inclusion (Dobusch 2012; Stieger et al. 2012; Tavakoli et al. 2015a); and the requirements of OSPM. The planning process includes the following three phases:

Pre-planning: This phase entails all activities required before the official start of the planning project including methodological and soft development of the rules governing the planning process. The following topics should be determined during this phase: the structure of the plan, participating stakeholders, communication approaches, and management support.

Idea submission: During this phase designated stakeholders will be asked to enter their ideas using the planning platform. This phase will start with a number of invitations sent to all designated stakeholders aiming to increase awareness and motives for participation. More than submitting ideas, designated stakeholders have the right to comment on others' ideas and a number of reviewers will later comment and/or score each idea before final submission of the idea to the plan development phase.

Plan development: Transformation of strategy ideas into the final strategic plan will start with qualitative theme analysis of the approved ideas resulting in assigning a number of codes to each idea. Each code will be then studied with project managers to see if the related theme can be approved as an objective in the final plan. The identified areas of improvement will also form goals in the plan. Finally by referring to the details on submitted ideas for each approved theme and related comments, approaches for achieving each objective will be introduced as strategies.

The components of OPSM together are designed to address the identified requirements in the study. For example, the communication layer of the architecture and plan development phase in the strategy process facilitates the transparency of planning ideas and planning output. For this reason the requirements have been considered as parts of the methodology facilitating the transparency requirement. Table 2 maps various components of the planning system with the relevant design requirements they deal with. 


\begin{tabular}{|l|l|l|l|l|l|l|}
\hline \multirow{2}{*}{$\begin{array}{l}\text { Requirements } \\
\text { from Table } 1\end{array}$} & 4.1 Components of planning system & \multicolumn{4}{l|}{ 4.2 Components of planning process } \\
\hline & Communication & $\begin{array}{l}\text { Idea } \\
\text { submission }\end{array}$ & Workflow & $\begin{array}{l}\text { Pre- } \\
\text { planning }\end{array}$ & $\begin{array}{l}\text { Idea } \\
\text { submission }\end{array}$ & $\begin{array}{l}\text { Plan } \\
\text { development }\end{array}$ \\
\hline Inclusion & $\square$ & $\square$ & $\square$ & $\square$ & $\square$ & \\
\hline Transparency & $\square$ & & & & & $\square$ \\
\hline Give equal voice & $\square$ & $\square$ & & & $\square$ & \\
\hline Avoid deception & $\square$ & $\square$ & & & $\square$ & \\
\hline Avoid coercion & $\square$ & $\square$ & & & $\square$ & \\
\hline
\end{tabular}

Table 2. Mapping design requirements and components of the planning system

As depicted in Table 2, each requirement has been satisfied by at least one component of the planning system and one component of the planning process. As explained before, OSPM is developed in a way to reflect the elements of ISDT. This study covers all of the elements of ISDT as suggested by Gregor and Jones (2007). For example the purpose and scope of the study have been identified, the principles of form and function are explained through a multilayer architecture for planning system which facilitates open strategic planning in an online discourse environment, and principles of implementation are provided in form of a three phase strategy process.

As illustrated in Error! Reference source not found., OSPM reflects all elements of an ISDT in addressing the main research aim. The developed methodology implemented Habermasian discourse theory and relevant requirements have been developed based on that through the proposed architecture and/or the process. The abstraction level in OSPM also makes the methodology applicable to a variety of contexts. The following section reports on an application of the methodology in two cases and an evaluation on how the requirements were achieved in each case.

\section{Instantiations of the Methodology in two Cases}

In accordance with the evaluation phase in DSR (Peffers et al. 2007), the proposed methodology (OSPM) was applied and implemented in two case studies in different contexts. This section reports on the relevancy and fit of the method in each case, and how the design requirements were addressed. . The effectiveness of the strategic plan and the planning process were also evaluated through a number of interviews with stakeholders in both cases. Due to page limitations, the results of this evaluation are not reported in this paper. A summary of possible implementation challenges however are reported on.

The first case was an open source software project with almost 200 potential stakeholders among three groups of managers, (software and service) developers, and users. After initial agreements, all of designated stakeholders were then invited to participate in developing the strategic plan. After two months, a total number of 78 ideas and comments were submitted in the planning system. According to the design method, the next phase of the project was an analysis of themes in submitted ideas. This resulted in identification of 34 themes, which were then submitted to project managers for scrutiny and they were asked to approve / reject each theme to be considered in the strategic plan. Approved ideas formed the final strategic plan in this case.

The second case was conducted in a not-for-profit organization dedicated to provide lifelong educational services for seniors. Four groups of managers, volunteers, tutors, and members were invited to participate. From more than 500 expected participants, almost 100 ideas were submitted after which further discussions formed a strategic plan compromising four goals, ten objectives, and 27 strategies. Although in both cases stakeholders were given the opportunity to view and comment on the submitted ideas, it was managers who had responsibility and the authority to consider a certain idea in the final version of the developed plan and to approve the plan. Table 3 describes the results of an evaluation with regards to each of the identified requirements. 


\begin{tabular}{|c|c|c|}
\hline $\begin{array}{ll}\text { Requirement } & \text { from } \\
\text { Table } 1 & \\
\end{array}$ & Case 1: Open source software & Case 2: not-for-profit organization \\
\hline $\begin{array}{lr}\text { Inclusion } & \text { (avoid } \\
\text { exclusion) } & \text { of } \\
\text { stakeholders } & \\
\end{array}$ & $\begin{array}{l}\text { Almost } 40 \% \text { of the stakeholders } \\
\text { submitted their ideas. }\end{array}$ & $\begin{array}{l}\text { Almost } 20 \% \text { of the stakeholders } \\
\text { submitted their ideas. }\end{array}$ \\
\hline $\begin{array}{l}\text { Transparency of the } \\
\text { strategic plan and } \\
\text { planning process }\end{array}$ & $\begin{array}{l}\text { All of the designated stakeholders } \\
\text { were contacted and invited to } \\
\text { participate. The planning process was } \\
\text { described for them in the invitation. } \\
\text { The final plan was published on the } \\
\text { planning system. }\end{array}$ & $\begin{array}{l}\text { All of the designated stakeholders } \\
\text { were contacted and invited to } \\
\text { participate. More than } 30 \% \text { of } \\
\text { stakeholders participated in an } \\
\text { introductory workshop. The planning } \\
\text { process was described for them in the } \\
\text { invitation. The final plan was sent to } \\
\text { all designated participants. }\end{array}$ \\
\hline $\begin{array}{l}\text { Give equal voice to } \\
\text { all stakeholders }\end{array}$ & \multirow{3}{*}{$\begin{array}{l}\text { All of the participants who could } \\
\text { potentially participate were contacted } \\
\text { and given the opportunity to submit } \\
\text { their ideas. } \\
\text { All of the participants had the choice } \\
\text { to submit their ideas anonymously. } \\
\text { However, some of the ideas could } \\
\text { possibly reveal the identity of } \\
\text { submitter. }\end{array}$} & \multirow{3}{*}{$\begin{array}{l}\text { All of the members who could } \\
\text { potentially participate were contacted } \\
\text { and given the opportunity to submit } \\
\text { their ideas. } \\
\text { All of the participants had the choice } \\
\text { to submit their ideas anonymously. }\end{array}$} \\
\hline $\begin{array}{l}\text { Avoid deception or } \\
\text { self-deception }\end{array}$ & & \\
\hline Avoid coercion & & \\
\hline
\end{tabular}

Table 3. How the requirements are satisfied in each case

Although the methodology achieved its goals and fulfilled the identified requirements, a number of challenges were identified during the implementation that should be considered in future practices. To improve future practices, a number of suggestions were also made in order to motivate more stakeholders to participate in the planning process. Suggestions included: increasing the number of face-to-face meetings and informative sessions during the pre-planning phase, keeping potential participants updated, and reminding participants about the project during idea submission and refinement phase. The results indicated that some of the developers lacked self-confidence to participate in the strategic planning or felt they were not in an equal power position to contribute. These reasons have been mentioned as barriers for inclusion of stakeholders in the strategy process (Eppler and Platts 2009; Hjortsø 2004).

\section{Discussion and Conclusion}

Although the concept of open strategy has been recognized as a facilitator for strategic planning throughout the literature, no comprehensive and theory based methodology have been developed in the literature for implementation of the concept in organizational environment. This paper tackled this shortcoming and has accomplished its aim. First, it has developed a methodology for strategic planning based on the notion of open strategy by considering discourse theory as a theoretical base to form the requirements. Open strategy was identified with three broad concepts: use of IT, inclusiveness, and transparency among OSPM yielding considerable facilitation for the first two components with a planning system architecture and process. Implementing the concept of transparency is however more challenging in a methodology as it is mixed with organizational power (Whittington et al. 2011).The proposed methodology has been successful to ensure transparency of strategy input (strategy ideas) and strategy output (the plan) according to the process definition of transparency in (Tavakoli et al. 2015a).

\section{Contributions}

The four pragmatic presuppositions of an ideal discourse were used as a theoretical lens to understand the requirements of an open strategy system. A review of the developed methodology and the two instantiations indicate that some aspects are well fulfilled in OSPM. For example anonymous idea submission through an online system provided equal voice for all participating stakeholders to submit their strategy ideas, comment on other ideas, and gave them freedom to do so. Effective communication 
with all possible stakeholders and their motivation for contribution in the planning system was a challenge requiring further study.

However, a pure hierarchy-free discourse is less attainable in a hierarchical organizational situation as a result of diverse goals for different stakeholders (Aier et al. 2011). For this reason, some aspects of the proposed methodology and its implementation in practice could deviate from the theory with the aforesaid presuppositions: The main difference could be granting more power to managers to make the final decision or approve the submitted idea. This power play may be criticized as a type of coercion in this process. Nevertheless, it should be considered that the right to make decisions with regard to strategy was excluded from the concept of open strategy (Whittington et al. 2011) and included in strategic planning (Mantere and Vaara 2008). The same concept could be applied to other areas in which managers have power over other stakeholders in OSPM such as: selecting stakeholders, and developing a format for strategy ideas.

The methodology covers architecture for a planning system and a planning process. Although online systems of strategic planning (Liinamaa et al. 2004) and open strategy processes (Dobusch 2012; Stieger et al. 2012; Tavakoli et al. 2015a) have been suggested in previous studies, no study to date have combined these two aspects in one single approach that can be applicable to various contexts and have been empirically developed and evaluated. Finally the proposed methodology goes beyond the idea submission task (that has been over studied in the previous literature) and the activities required before and after that for formulation of the plan as well as a recommended architecture for the planning system. Table 4 compares OSPM with previous studies of open strategic planning.

\begin{tabular}{|c|c|c|c|c|c|}
\hline \multicolumn{2}{|l|}{ OSPM } & $\begin{array}{l}\text { Liinamaa et al. } \\
\text { (2004) }\end{array}$ & $\begin{array}{l}\text { Stieger et al. } \\
(2012)\end{array}$ & Dobusch (2012) & $\begin{array}{l}\text { Tavakoli et al. } \\
\text { (2015a) }\end{array}$ \\
\hline \multirow{3}{*}{ 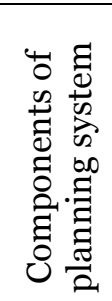 } & $\begin{array}{l}\text { Communic } \\
\text { ation }\end{array}$ & Dialogue tool & - & Communicating & - \\
\hline & $\begin{array}{l}\text { Idea } \\
\text { submission }\end{array}$ & $\begin{array}{l}\text { Questionnaire } \\
\text { tool }\end{array}$ & - & - & - \\
\hline & Workflow & Planning tool & - & - & - \\
\hline \multirow{3}{*}{ 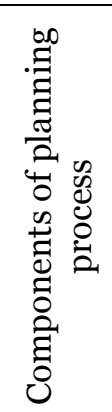 } & $\begin{array}{l}\text { Pre- } \\
\text { planning }\end{array}$ & - & Energizing & $\begin{array}{l}\text { Setting-up } \\
\text { Analyzing }\end{array}$ & $\begin{array}{l}\text { Staffing / Stage } \\
\text { setting } \\
\text { Announcing }\end{array}$ \\
\hline & $\begin{array}{l}\text { Idea } \\
\text { submission }\end{array}$ & - & $\begin{array}{lr}\text { Listening } & \text { and } \\
\text { talking } & \text { / } \\
\text { Supporting } & \end{array}$ & Generating ideas & Contributing \\
\hline & $\begin{array}{l}\text { Plan } \\
\text { developme } \\
\text { nt }\end{array}$ & - & $\begin{array}{l}\text { Embracing } \\
\text { employees }\end{array}$ & $\begin{array}{l}\text { Decision making } \\
\text { and synthesizing }\end{array}$ & Discussing \\
\hline
\end{tabular}

Table 4. OSPM vs. previous approaches of open strategic planning

As depicted in Table 4, the level of comprehensiveness in OSPM (dealing with both of aspects of planning system and planning process) cannot be found in other references. Another contribution of the research is to provide a level of abstraction in the developed methodology permitting its application in various contexts and with different technologies.

\section{Implications}

The current study has a number of implications for both practice and academia. In terms of academic implications, the study implemented discourse theory in the context of strategic planning in general and open strategy in particular. Although discourse theory has been frequently used in IS research and similar 
concepts (such as communicational process) have been subject of attention in strategic management research, to the best of our knowledge, this is the first study focusing on implications of Habermasian theory in strategic planning. This study recognizes similarities between Habermas' discourse and the open strategy concept and calls for future theoretical and empirical study of the open strategy concept and similar theory such as the theory of communicative action (Habermas 1985).

Although the open strategy concept has its roots in the IS domain, only limited studies have been published in IS outlets (Tavakoli et al. 2015a). Application of DSR perspective in the current study and specially employing elements of ISDT revealed the relevancy of IS research and related methods in the area of open strategy. As the main focus of the study is on the development of the information system and implementation of that, future IS researchers (especially those interested in open innovation) should consider open strategy as a new significant field of research.

The study can have several implications for practitioners as well. First and the most important practical implication of the study is creating a comprehensive methodology for implementing the concept of open strategy through an IT system. This methodology is applicable to various contexts and can facilitate development of strategic plan in an organization through a broader range of ideas. Moreover, as the ideas in the OSPM come from the people who are in charge of implementing the final strategic plan, the plan developed with this methodology is expected to be implemented more smoothly. Although the reported cases in the current study were in early stages of implementation at the time of preparing this paper, post implementation studies reported higher level of perceived success for the planning methodology and the developed plans. Instantiations of OSPM in two cases also helped this study to go beyond a theoretical methodology and report some of the possible implementation challenges. These challenges may occur in future applications of the methodology and the study contains advice on how to avoid them.

\section{REFERENCES}

Aier, S., Fischer, C., and Winter, R. 2011. "Theoretical Stability of Information Systems Design Theory Evaluations Based Upon Habermas's Discourse Theory," European Conference on Information Systems (ECIS).

Amrollahi, A. 2015. "A Process Model for Crowdsourcing: Insights from the Literature on Implementation," in: Australasian Conference on Information Systems: ACIS 2015. Adelaide.

Amrollahi, A., Ghapanchi, A., and Talaei-Khoei, A. 2014a. "Using Crowdsourcing Tools for Implementing Open Strategy: A Case Study in Education," Twentieth Americas Conference on Information System (AMCIS 2014), Savannah, USA, pp. 1-7.

Amrollahi, A., and Ghapanchi, A.H. 2016. "Open Strategic Planning in Universities: A Case Study," in: 49th Hawaii International Conference on System Sciences (HICSS). Koloa, USA: IEEE, pp. 386395.

Amrollahi, A., Ghapanchi, A.H., and Talaei-Khoei, A. 2014b. "From Artefact to Theory: Ten Years of Using Design Science in Information Systems Research," Proceedings of the 13th European Conference on Research Methodology for Business and Management Studies: ECRM 2014), p 383.

Bjelland, O.M., and Wood, R.C. 2008. "An inside View of Ibm's' Innovation Jam'," MIT Sloan management review (50:1), pp 32-40.

Bohman, J., and Rehg, W. 2007. "Jürgen Habermas." Stanford Encyclopedia of Philosophy, from http://stanford.library.usyd.edu.au/archives/spr2012/entries/habermas/

Chiasson, M., and Davidson, E. 2012. "Reconsidering Deconstruction in Information Systems Research," European Journal of Information Systems (21:2), pp 192-206.

Dobusch, L. 2012. "Strategy as a Practice of Thousands: The Case of Wikimedia," Academy of Management Proceedings: Academy of Management, pp. 1-6.

Dobusch, L., and Kapeller, J. 2013. "Open Strategy between Crowd and Community: Lessons from Wikimedia and Creative Commons," Academy of Management Proceedings: Academy of Management, p. 15831.

Eppler, M.J., and Platts, K.W. 2009. "Visual Strategizing: The Systematic Use of Visualization in the Strategic-Planning Process," Long Range Planning (42:1), pp 42-74.

Gregor, S., and Jones, D. 2007. "The Anatomy of a Design Theory," Journal of the Association for Information Systems (8:5), pp 312-335. 
Habermas, J. 1985. The Theory of Communicative Action, Volume 2: Lifeworld and System: A Critique of Functionalist Reason. Boston: Beacon Press.

Habermas, J. 2005. Zwischen Naturalismus Und Religion. Frankfurt am Main: Suhrkamp.

Hamel, G. 1996. "Strategy as Revolution," Harvard Business Review (74:4), pp 69-82.

Hjortsø, C.N. 2004. "Enhancing Public Participation in Natural Resource Management Using Soft or--an Application of Strategic Option Development and Analysis in Tactical Forest Planning," European Journal of Operational Research (152:3), pp 667-683.

Liinamaa, K., Nuutinen, J.A., Sutinen, E., and Vanharanta, H. 2004. "Collaborative Strategic Planning onLine," PsychNology Journal (2:2), pp 242-254.

Mantere, S., and Vaara, E. 2008. "On the Problem of Participation in Strategy: A Critical Discursive Perspective," Organization Science (19:2), pp 341-358.

March, S.T., and Smith, G.F. 1995. "Design and Natural Science Research on Information Technology," Decision Support Systems (15:4), pp 251-266.

Matzler, K., Füller, J., Koch, B., Hautz, J., and Hutter, K. 2014. "Open Strategy-a New Strategy Paradigm?," in: Strategie Und Leadership. Springer, pp. 37-55.

Mintzberg, H. 1994. "Rethinking Strategic Planning Part Ii: New Roles for Planners," Long Range Planning (27:3), pp 22-30.

Morton, J., Wilson, A., and Cooke, L. 2015. "Collaboration and Knowledge Sharing in Open Strategy Initiatives," iFutures 2015, Sheffield, UK, pp. 1-7.

Peffers, K., Tuunanen, T., Rothenberger, M.A., and Chatterjee, S. 2007. "A Design Science Research Methodology for Information Systems Research," Journal of Management Information Systems (24:3), pp 45-77.

Spee, A.P., and Jarzabkowski, P. 2011. "Strategic Planning as Communicative Process," Organization Studies (32:9), pp 1217-1245.

Stefanou, C.J. 2001. "A Framework for the Ex-Ante Evaluation of Erp Software," European Journal of Information Systems (10:4), pp 204-215.

Stieger, D., Matzler, K., Chatterjee, S., and Ladstaetter-Fussenegger, F. 2012. "Democratizing Strategy: How Crowdsourcing Can Be Used for Strategy Dialogues," California Management Review (54:4), pp 44-68.

Tavakoli, A., Schlagwein, D., and Schoder, D. 2015a. "Open Strategy: Consolidated Definition and Processual Conceptualization," in: Thirty-Sixth International Conference on Information Systems. Fort Worth, USA: pp. 1-12.

Tavakoli, A., Schlagwein, D., and Schoder, D. 2015b. "Open Strategy: Towards a Shared Understanding," in: Developmental Workshop on Open Research and Practice in IS. Münster, Germany: pp. 1-5.

Walls, J.G., Widmeyer, G.R., and El Sawy, O.A. 1992. "Building an Information System Design Theory for Vigilant Eis," Information Systems Research (3:1), pp 36-59.

Whittington, R., Cailluet, L., and Yakis-Douglas, B. 2011. "Opening Strategy: Evolution of a Precarious Profession," British Journal of Management (22:3), pp 531-544.

Wolf, C., and Floyd, S.W. 2013. "Strategic Planning Research toward a Theory-Driven Agenda," Journal of Management), pp 1-35. 